\title{
O AMBIENTE AMANDA: uma referência para intensificar a interatividade em fóruns com mediação automatizada
}

\section{THE AMANDA ENVIRONMENT: a reference to intensify the interactivity in forums with automatized mediation}

Silma Côrtes da Costa Battezzati ${ }^{1}$

Flávio Bortolozzi ${ }^{2}$

\section{Resumo}

Este artigo apresenta as características do Ambiente Virtual AMANDA Ambiente de Mediação à Análise de Discussões Argumentativas, desenvolvido para mediar discussões em grupo e reduzir problemas de falta de interatividade em fóruns. O AMANDA é um sistema inovador que organiza em árvores estruturadas, por meio da aplicação de técnicas de inteligência computacional, as discussões argumentativas dos membros que trocam informações em ambientes de comunicação mediada por computador- CMC, em modalidade assíncrona. É um ambiente virtual inteligente, pois a mediação das discussões se dá totalmente por algoritmos, dispensando a interferência contínua de um mediador humano e facilitando o trabalho dos professores em atividades de aprendizagem colaborativa. Uma das principais vantagens do AMANDA é permitir que, por meio das fichas de discussões, as pessoas possam debater assuntos diferentes ao mesmo tempo. Para avaliar como a mediação automatizada por AMANDA poderia intensificara interação e a externalização do conhecimento entre estudantes em fóruns voltados a atividades de aprendizagem colaborativa, realizamos, no ano de 2002, uma

\footnotetext{
Mestre em Educação pela Pontifícia Universidade Católica do Paraná, Pedagoga pela UTP. E-mail: silmafao@yahoo.com.br

2 Ph.D. em Engenharia de Controle de Sistemas, Universite de Technologie de Compiegne, França; Engenheiro Civil, e Matemático, Pontifícia Universidade Católica do Paraná (PUCPR), Pró-Reitor de Pesquisa e Pós-Graduação, professor e pesquisador dos programas de Mestrado em Informática Aplicada e do Programa de Mestrado em Educação da PUCPR, Rua Imaculada Conceição, 1155, Prado Velho, Curitiba - PR, CEP 80.215-901

E-mail: fborto@ppgia.pucpr.br
} 
experiência com um grupo de alunos do Programa de Mestrado em Educação da PUCPR. Nessa atividade consideramos a importância de alguns mecanismos apresentados na Teoria da Criação do Conhecimento Organizacional (1997). Os resultados da experiência demonstraram que o AMANDA apresentou desempenho satisfatório na automação do encaminhamento das questões e dos argumentos, sem a necessidade da intervenção do professor e para provocar a externalização de conhecimentos, por meio de acordos ou desacordos, integrais ou parciais, entre os estudantes.

Palavras-chave: Aprendizagem colaborativa; Comunicação mediada por computador (CMC); Ambiente AMANDA; Interatividade; Argumentação; Externalização de conhecimento explícito.

\section{Abstract}

This article presents the characteristics of AMANDA - Ambiente de Mediação à Análise de Discussões Argumentativas, a virtual environment developed to mediate group discussion and improve interactivity during forum discussions. AMANDA is an innovating system that organizes, in structured trees, the argumentative discussions of the members of an exchange information group, using the asynchronous mode of Computer Mediated Communication - CMC, by applying computational intelligence techniques. It is considered an intelligent virtual environment since the mediation of the discussions is done by algorithms, free of continuous human interference, therefore helping teachers with the activities of collaborative learning. One of the main advantages of AMANDA is the possibility that people have to debate different subjects at the same time, using different discussion cards. In order to measure how mediation automated by AMANDA could intensify student's interaction and externalization of knowledge, using forums for collaborative learning activities, we realized, at the year of 2000, an experiment with a group of students from the Masters of Education program at PUCPR. At the experiment we have considered the importance of some mechanisms introduced by Nonaka's Theory of Organization Knowledge Creation. The experiment showed thatAMANDA presented satisfactory results on the auto matic delivery of the questioning and resulting arguments, without the need for teacher's interference, and helped challenge the extemalization of knowledge from the students, by means of requesting agreements or disagreements answers, complete or partial, among them.

Keywords: Collaborative leaming; Computer mediated communication (CMC); AMANDA environment; Interactivity; Argumentation; Externalization of knowledge. 


\section{Introdução}

A formação de grupos que têm como objetivo compartilhar informações utilizando-se dos novos recursos da comunicação mediada por computador - CMC parece ser cada vez mais freqüente na sociedade contemporânea, devido à popularização da Internet e da Web.

Originalmente, o primeiro método de comunicação mediada por computador - CMC, desenvolvido para facilitar contatos e processos de tomada de decisões a partir da troca de idéias e informações entre grupos de especialistas, é o método Delphi.

O Delphi foi desenvolvido nos anos 50 pela United States Air Force USAF - Força Área Americana e patrocinado pela empresa Rand Corporation, dos Estados Unidos, com o objetivo de produzir maior interação entre grupos de pesquisadores que faziam previsões a respeito de temas internacionais ligados à área militar.

A primeira experiência em conferência mediada por computador com Delphi, administrada pelo Escritónio de Preparação de Emergência dos EUA, foi realizada em 1970. A conferência on-line aconteceu durante treze semanas e envolveu vários especialistas, em diversos pontos dos Estados Unidos, que usaram terminais de computadores conectados a linhas telefônicas para participarem do exercício em Delphi. Atualmente, em diversos países, o Delphi passou a ser aplicado como procedimento de predição no campo empresarial, de novas tecnologias, na sociologia e na saúde. Nesse contexto, a técnica Delphi é definida como um método que estrutura os processos de comunicação mediada por computador entre grupos que discutem problemas complexos e objetivam disseminar conhecimentos. A partir da metade da década de 1990, com o crescente uso da Internet e da Web, novos ambientes virtuais de CMC começaram a ser criados na maioria das universidades do mundo, geralmente com o objetivo de intensificar o contato a distância entre professores e estudantes e, mais recentemente, para facilitar a realização de experiências de ensino e aprendizagem.

Neste contexto, quando grupos de professores e estudantes se comunicam por meio do computador, em ambientes virtuais de CMC, podem utilizar diversas ferramentas síncronas e assíncronas de comunicação, como 0 chat, o correio eletrônico e os fóruns. As interações síncronas são aquelas nas quais as pessoas estão on-line, todas ao mesmo tempo, em salas de bate papo ou Chat, por exemplo. Já as interações assíncronas, como o correio eletrônico e os fóruns, são aquelas em que a comunicação não acontece em tempo real, mas permitem que as informações, mensagens e demais dados fiquem disponíveis ao usuário e podem ser acessados no momento em que este se conecta à Internet. No contexto educacional, os fóruns se caracterizam como um re- 
curso de CMC desenvolvido para estimular diálogos interativos entre estudantes, pois permite que estes possam ler ou explicitar idéias e pensamentos nos momentos que considerarem mais apropriados.

Embora o fórum seja um dos meios de CMC preferido para a troca de informações entre os alunos, em algumas experiências de aprendizagem é utilizado apenas como espaço para consulta de conteúdos escolares ou como suporte para a distribuição de materiais didáticos pelos professores. Quando isso acontece, a interatividade e o diálogo, que são fatores-chave para o sucesso de um fórum, ficam prejudicados, pois a simples cópia ou transmissão de conteúdos reforça o modelo tradicional de ensino. Modelo no qual o professor é apenas o transmissor de conteúdos e os estudantes meros receptores dessas informações.

Considerando que o uso de fóruns é relativamente novo no meio educacional brasileiro e que suas implicações para estimular a comunicação e o diálogo entre os estudantes, durante atividades de aprendizagem, ainda são objeto de grandes discussões, a PUCPR desenvolveu, em parceira com a Universidade de Tecnologia de Compiègne (UTC-França), um método e um sistema computacional denominado AMANDA - Ambiente de Mediação à Análise de Discussões Argumentativas, com o objetivo de reduzir problemas de falta de interatividade em fóruns.

O AMANDA é um sistema que organiza e realiza automaticamente a mediação de discussões argumentativas por meio de CMC em modalidade assíncrona e, por basear-se no encaminhamento automático de questões e solicitação de argumentações, tem o propósito de provocar a externalização de conhecimentos entre os participantes de um fórum. Segundo A Teoria da Criação do Conhecimento Organizacional, de Nonaka e Tekeuchi (1997), a externalização é o modo de conversão do conhecimento tácito em conhecimento explícito e é fundamental para o compartilhamento ou socialização de novos conceitos em atividades de ensino mediadas por computador.

Para avaliar o desempenho do AMANDA, foi realizado um fórum de discussão com um grupo de alunos do Programa de Mestrado em Educação da PUCPR, no ano de 2002. Devido ao fato do AMANDA possuir um método inovador, em que a mediação de um professor real pode ser realizada por um professor virtual, algumas questões foram problematizadas diante da perspectiva de seu uso para a realização de atividades de aprendizagem na PUCPR. Uma dessas questões buscava esclarecer como a mediação automatizada pelo sistema AMANDA poderia intensificar a interação e a externalização do conhecimento entre estudantes em fóruns voltados a atividades de aprendizagem colaborativa.

Este texto apresenta, com maiores detalhes, as características do ambiente AMANDA, a dinâmica e os resultados da experiência realizada. 


\section{0 ambiente AMANDA - uma breve descrição}

Atualmente, o computador tem sido muito utilizado com fins educativos em diversas instituições de ensino do mundo. Neste cenário, os fóruns são uma das ferramentas mais utilizadas por professores e estudantes para a realização de atividades de aprendizagem colaborativa em ambientes de CMC, uma metodologia de ensino que têm como objetivo estimular a participação e a troca de experiências entre os aprendizes com o propósito de construírem novos conhecimentos.

Entretanto, em muitas dessas experiências não ocorre comunicação interativa entre os estudantes, que utilizam o fórum apenas para consultar ou copiar conteúdos. Diante da problemática com a baixa participação dos alunos em fóruns, alguns professores pesquisadores buscam soluções que permitam modificar esse quadro de apatia para incentivar maior interatividade entre os alunos em fóruns, sem que para isso tenham que gastar horas à frente de terminais de computador para motivar essa participação. Este é o objetivo do ambiente virtual AMANDA que "Tem como propósito mediar discussões em grupos e baseia-se em modelos de domínio e estruturas de argumentação. Modelos de domínio são usados para gerar questões em linguagem natural para debates em grupos e estruturas argumentativas visam criar um contexto de diálogo altamente interativo para que os participantes de um fórum discutam as questões propostas". (ELEUTERIO, 2002, p.2).

Uma das principais vantagens do AMANDA é possibilitar que várias pessoas possam, anonimamente, discutir assuntos diferentes ao mesmo tempo. Nesse aspecto , o sistema assemelha-se a um fórum de discussão inteligente, pois a mediação das discussões se dá totalmente por algoritmos, dispensando a interferência contínua de um mediador humano. Conforme Eleuterio (2002), "o anonimato é desejável quando se pretende que os participantes reajam ao conteúdo, ao assunto discutido, e não aos autores das contribuições".

Portanto, durante um fórum de discussões, o AMANDA organiza em árvores estruturadas, por meio da aplicação de técnicas de inteligência computacional, as discussões argumentativas dos membros de grupos que se comunicam por meio de CMC em modalidade assíncrona. A colaboração, o diálogo e a externalização anônima de idéias ou opiniões entre os estudantes formam a árvore de argumentação, uma coleção estruturada de perguntas, alternativas e argumentos que evoluem ao longo de ciclos de diálogos.

Uma visão simplificada do que seja uma árvore estruturada de discussões pode ser compreendida como um espaço reservado no computador no qual estão armazenadas as questões que serão debatidas pelo grupo de discussão e as suas respectivas respostas ou externalizações. 
Graficamente isso equivaleria a um desenho no qual a pergunta é representada por um círculo (nó) e nesse nó ficam ligados outros círculos que representam as diversas respostas ou argumentações. Por exemplo, se imaginarmos uma pergunta que foi encaminhada para 10 participantes em um fórum, identificados pelas siglas ID2, ID11, ID13 e etc., teremos uma figura (árvore invertida), como a apresentada a seguir, que inicia com um círculo. Este primeiro círculo representa a pergunta (DE-1). Abaixo deste ficarão outros círculos ligados por meio de linhas, ou seja, na primeira linha os círculos representam as respostas apresentadas para a pergunta (R1 a R11). Na segunda, terceira e quarta linhas os círculos representam as argumentações externalizadas para cada resposta (ARG), os níveis de interações.

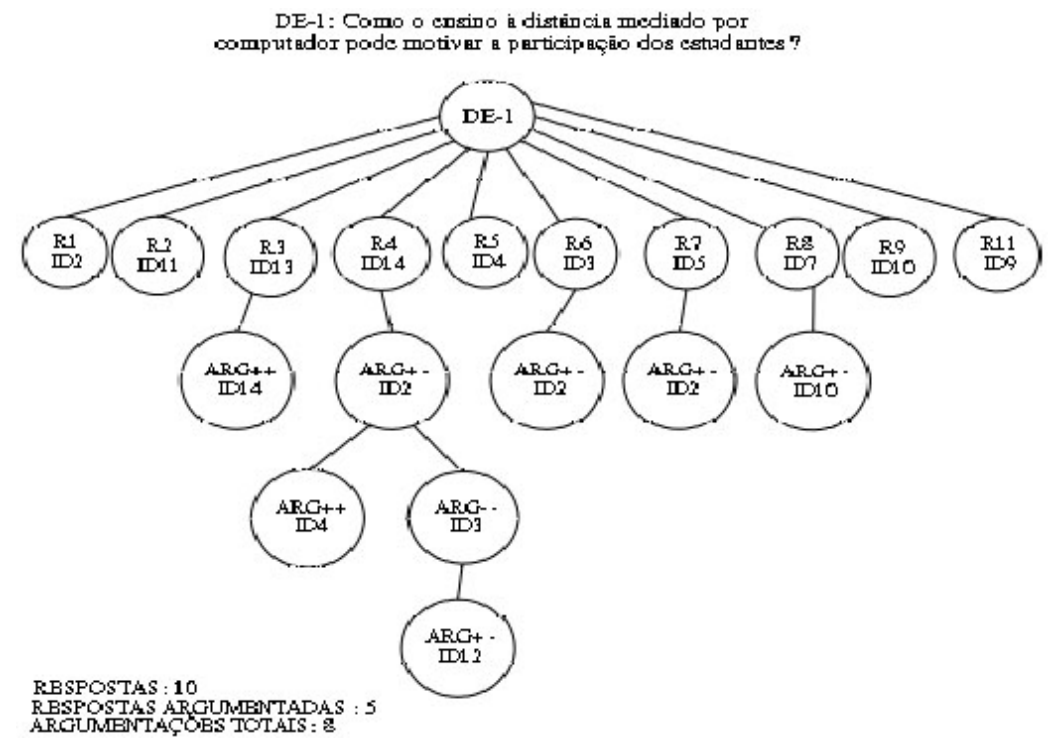

Figura 1: Árvore estruturada em Fórum com AMANDA

Em um fórum com AMANDA, os participantes recebem, por e-mail, fichas de discussões (figura 2), para serem respondidas e argumentadas. Após este procedimento, as fichas são enviadas de volta para o sistema, que então estrutura a árvore. Desse modo, ao início de cada ciclo, que representam as rodadas de discussões, os estudantes recebem novas fichas de discussões, algumas contendo questões para serem respondidas, externalizadas, pela primeira vez e outras contendo questões que já foram externalizadas em outros ciclos, para serem novamente argumentadas. Esse processo se repete até 0 término do fórum, segundo estabelecido pelo professor. 


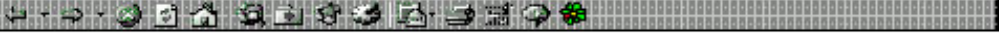

\section{Ficha de Discussão}

Curso: Tesis SilmaPeulo (sycle 1)

1

Q: Quel á e etitude meis importertia e ser bomede pelo professar ed plenejer um fórurn de discussäes? Jusunque.

อะra rebporta...

Ii

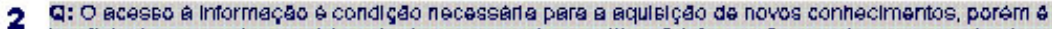
Insuficiente para a desenvoNimento do pensamenta cognitlwo. A Imformaça para tomar-se connecimento deve ser previamente selecianeda e interpretede pera que o estudarnte passa lhe atribuir significetiva relaçê com as saberes escolares. Como professor, quais as estratésias considera mais adequades pera auxiliar os estudantes a seleclonarem Informaçoes na WEB?. Justlnque.

sua resposta $\ldots$

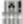

i.

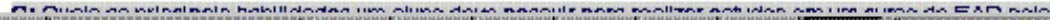

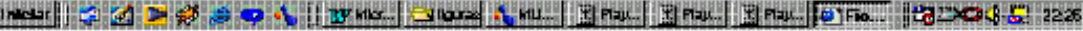

Figura 2 - Ficha de discussões do AMANDA.

Um outro objetivo do AMANDA é o de diminuir o trabalho de mediador do professor, que pode intervir nas discussões como um participante normal ou apenas quando houver polêmica. Por exemplo, se diante de uma questão um participante discorda integralmente da resposta dada por outro participante, e um terceiro concorda integralmente com a mesma resposta, gerando com isso alto grau de polemicidade, o sistema requisita a intervenção do professor para avaliar o argumento que gerou a polêmica e, por meio de feedback, compartilhar significados que irão esclarecer e validar a resposta ou o argumento correto para a questão polemizada.

É importante frisar que o AMANDA privilegia pontos de vista polêmicos numa discussão, visando assim a assegurar uma efetiva participação do grupo sobre os assuntos propostos. Todavia, como o sistema não analisa os argumentos das discussões com relação ao seu conteúdo semântico, as argumentações são classificadas a partir de operações computacionais, em forma de algoritmos, conforme o grau de concordância dos argumentos apresentados para cada questão. Assim, para que possa externalizar seu grau de acordo ou desacordo em relação a uma determinada idéia, o participante do fórum escolhe uma das cinco opções, disponibilizadas pelo sistema. São elas:

(1) Concordo (concordo $100 \%$ e não tenho nada a acrescentar) $=$ $(++)$. 
(2) Sim, mas... (concordo com a maior parte da idéia, mas quero acrescentar algo para reforçá-la) $=(+-)$.

(3) Não, porém... (não concordo com a maior parte da idéia) = $(-+)$.

(4) Discordo (não concordo com nenhum ponto da idéia) $=(--)$.

(5) Passo (não me sinto apto para participar desta linha de discussão).

Qualquer opção além de "concordo" e "passo" exige que o participante digite o seu argumento na área de texto, conforme demonstra a figura 2.

As cinco opções descritas permitem que o sistema selecione automaticamente as respostas emitidas pelos participantes, em cada ficha, e as relance aos membros do grupo para novas discussões. Em síntese, o sistema observa, de acordo com as opções escolhidas, o grau de polemicidade, gerado pelas respostas, e novamente as reenvia para serem discutidas, produzindo novos ciclos de discussões, até que o professor determine o final do fórum, ou à medida que o grau de polemicidade entre os participantes diminui. Este processo faz com que a cada rodada de discussões a árvore de contribuições - argumentações - vá aumentando, à medida que o sistema identifica conflitos entre as respostas - externalizações.

As questões que não apresentam respostas polêmicas perdem prioridade para o sistema que privilegia argumentações com baixo grau de concordância entre os participantes do grupo. Entretanto, com a extensão dos acordos parciais, o objetivo das discussões argumentativas em AMANDA deixa de ser uma disputa e possibilita a mediação de discussões em grupo. Logo, em um fórum com AMANDA não há um vencedor, ou um grupo de vencedores, nem uma alternativa prioritária para se discutir, todas apresentam o mesmo valor de importância.

A partir das explicações apresentadas, passamos a relatar a importância de alguns mecanismos apresentados na Teoria da Criação do Conhecimento Organizacional, de Nonaka e Takeuchi (1997), para o sucesso de um fórum com AMANDA.

\section{A Teoria da Criação do Conhecimento Organizacional: a importân- cia da externalização do conhecimento em fóruns com AMANDA}

A Teoria da Criação do Conhecimento Organizacional, de Nonaka e Tekeuchi (1997), postula que a colaboração é requisito básico para o desenvolvimento da aprendizagem e apresenta alguns mecanismos que possibilitam a geração de novos conhecimentos entre pessoas que trabalham ou estudam 
colaborativamente. Estes mecanismos, denominados socialização, externalização, combinação e internalização, permitem transformar conhecimentos tácitos em conhecimentos explícitos e vice-versa.

O conceito de conhecimento tácito foi introduzido pelo filósofo húngaro Michael Polanyi a partir da frase we can know more than we can tel - nós podemos saber mais do que nós podemos dizer. Polany apud Nonaka e Takeuchi (1997, p. 65-66) explica que há conhecimentos que internalizamos e utilizamos, mas que temos dificuldades em externalizar, logo, o conhecimento tácito é aquele existente em nossas mentes e que nem sempre pode ser explicitado, ou compartilhado por outras pessoas. São conhecimentos que temos dificuldade em explicar utilizando linguagem formal.

Os conhecimentos explícitos são aqueles que encontramos representados em alguma forma de mídia, tais como impressa, audiovisual ou em computadores. Representam um tipo de conhecimento declarado formalmente, que é facilmente transmissível em forma de dados brutos, fórmulas científicas, procedimentos codificados ou princípios universais. Segundo Nonaka e Takeuchi (1997, p. 8) "[...] para os ocidentais o conhecimento explícito é considerado um tipo de conhecimento que forma as regras que governam suas relações com a realidade e se expressa por meio de hábitos rotineiros ou procedimentos e comportamentos controlados".

O pressuposto de que o conhecimento é criado por meio da interação entre o conhecimento tácito e o conhecimento explícito levou os autores da Teoria da Criação do Conhecimento Organizacional (1997, p. 62) a postularem os quatro modos de conversão de conhecimento: socialização, externalização, combinação e internalização. Conforme veremos a seguir, esses modos representam os mecanismos pelos quais o conhecimento individual é articulado e amplificado entre os membros de um grupo.

O primeiro modo, denominado socialização, refere-se à conversão do conhecimento tácito em conhecimento tácito. É um mecanismo que facilita o compartilhamento de experiências e modelos mentais entre os membros de um grupo.

A externalização, modo de conversão do conhecimento tácito em explícito é, de acordo com Nonaka e Takeuchi (1997), considerada a chave para a criação de novos conceitos em atividades de ensino mediadas por computador, a exemplo de um fórum com AMANDA, uma vez que é provocada pela reflexão coletiva de significados, nos quais o emprego de uma metáfora ou analogia significativa ajuda os membros de um grupo a articularem o conhecimento tácito oculto que, de outra forma, é difícil de ser comunicado.

Conforme explicam Nonaka e Takeuchi (1997, p.71-74), uma metáfora consiste em dois pensamentos de coisas diferentes apoiados por uma única palavra, ou expressão, cujo significado é resultado de sua interação. A analo- 
gia é realizada pelo pensamento racional e concentra-se nas semelhanças, estruturais e/ou funcionais, entre duas coisas.

A combinação é o modo de conversão do conhecimento explícito em um novo conhecimento explícito. Este é, segundo Nonaka e Takeuchi (idem), o processo de conversão de conhecimentos preferido pelos ocidentais à medida que permite a explicitação rápida de informações por meio de reuniões formais, conversas telefônicas ou documentos.

O quarto e último modo, a internalização, é o processo de conversão do conhecimento explícito em conhecimento tácito. Esse é um processo complexo, pois para que o conhecimento explícito possa se transformar em tácito, é necessária a verbalização e a diagramação do conhecimento sob a forma de manuais ou histórias orais.

De forma sintetizada, podemos assim compreender as explicações de Nonaka e Takeuchi (1997 p. 80) sobre os quatro modos de conversão de conhecimentos.

Em primeiro lugar, o modo da socialização normalmente começa desenvolvendo um campo de interação. Esse campo facilita o compartilhamento das experiências e modelos mentais entre os membros de um grupo. Segundo, o modo de externalização é provocado pelo diálogo ou pela reflexão coletiva de significados, nos quais o emprego de uma metáfora ou analogia significativa ajuda os membros da equipe a articularem o conhecimento tácito oculto que, de outra forma, é difícil de ser comunicado. Terceiro, o modo de combinação é provocado pela colocação do conhecimento recém-criado e do conhecimento já existente em uma rede, sob a forma de manuais por exemplo. Por fim, o aprender fazendo provoca a internalização.

Os novos conhecimentos gerados pelos quatro modos de conversão apresentados se tornam o próximo patamar para o início de um novo processo de criação de conhecimentos, denominado por Nonaka e Takeuchi (1997) de Espiral do Conhecimento (figura 3).

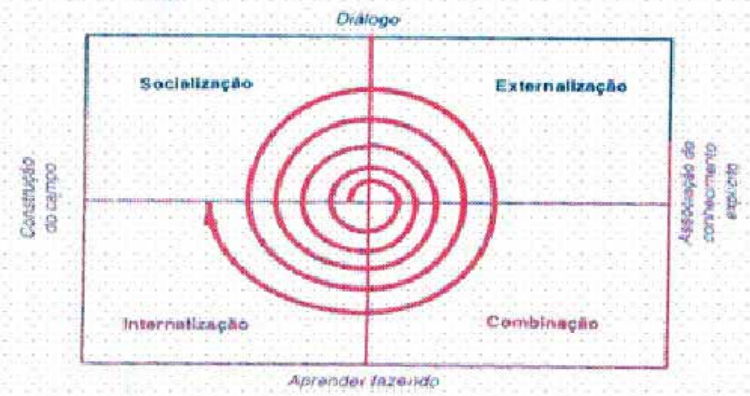

Figura 3 - Espiral de Criação do Conhecimento (Nonaka e Takeuchi, 1997, p. 80). 
Este processo em espiral começa no nível individual e vai gradativamente se expandindo e ampliando entre os membros de uma comunidade de interação. Num fórum com AMANDA, a externalização ocupa lugar de maior importância para a criação de novas espirais do conhecimento, pois permite que pessoas fisicamente distantes possam explicitar suas idéias e conhecimentos basicamente pela escrita.

\section{Fórum com AMANDA: uma experiência}

Na experiência realizada em 2002, com um grupo de alunos do Programa de Mestrado em Educação da PUCPR, os participantes receberam, durante sete ciclos de discussões, fichas individuais com questões para serem respondidas e argumentadas anonimamente. Cada ficha apresentava quatro questões que, depois de respondidas, eram enviadas de volta para o sistema.

A primeira rodada ou ciclo de discussões representa a fase em que os estudantes externalizaram suas idéias iniciais sobre o assunto em discussão no fórum, ou seja, sobre as principais características da educação a distância.

A partir do segundo ciclo, os participantes receberam novas fichas, algumas contendo novas questões para serem externalizadas pela primeira vez e outras contendo questões com argumentações de outros participantes, para serem novamente argumentadas. Algumas dessas questões, argumentações, receberam novas contribuições, outras não.

Este processo se repetiu do segundo ao sétimo ciclo de discussões, conforme estabelecido pelo professor. Ao término do fórum, os estudantes receberam, por e-mail, o relatório de resultados das discussões, enviado pelo próprio sistema.

Para analisar quantitativamente o desempenho do AMANDA no encaminhamento das questões e dos argumentos, a partir do relatório de resultado das discussões, elaboramos e apresentamos 15 figuras, "árvores", que demonstram o número de respostas - externalizações e argumentações ocorridas em cada ciclo de discussões, bem como os níveis de argumentação e os tipos de argumentações apresentadas no fórum.

Em relação aos aspectos qualitativos, avaliamos o desempenho e a funcionalidade do sistema para intensificar a interação e a externalização do conhecimento entre os estudantes e para facilitar o trabalho do professor. Nessa análise, consideramos os depoimentos apresentados pelos estudantes na entrevista realizada ao final da experiência. Entre as perguntas que fizemos aos estudantes, destacamos: quais foram as impressões sobre a utilidade do AMANDA para mediar o fórum? Como se sentiram discutindo anonimamente 
com os colegas? Como avaliam a atuação do professor, e se o AMANDA facilita mesmo seu trabalho? Quais as dificuldades que cada um sentiu no momento de responder, externalizar suas opiniões durante o fórum?

De forma geral, os estudantes responderam que a participação no fórum mediado por AMANDA foi muito interessante, pois nunca haviam participado de uma experiência em fórum em que um sistema computacional distribuísse questões para debate.

Portanto, as conclusões desta pesquisa emergiram, em parte, dos resultados da análise qualitativa e, em parte, dos resultados da análise quantitativa.

Para ilustrar, de modo resumido, como procedemos à análise quantitativa dos resultados do fórum, apresentamos o exame da questão 1 - figura 1: Árvore estruturada em Fórum com AMANDA.

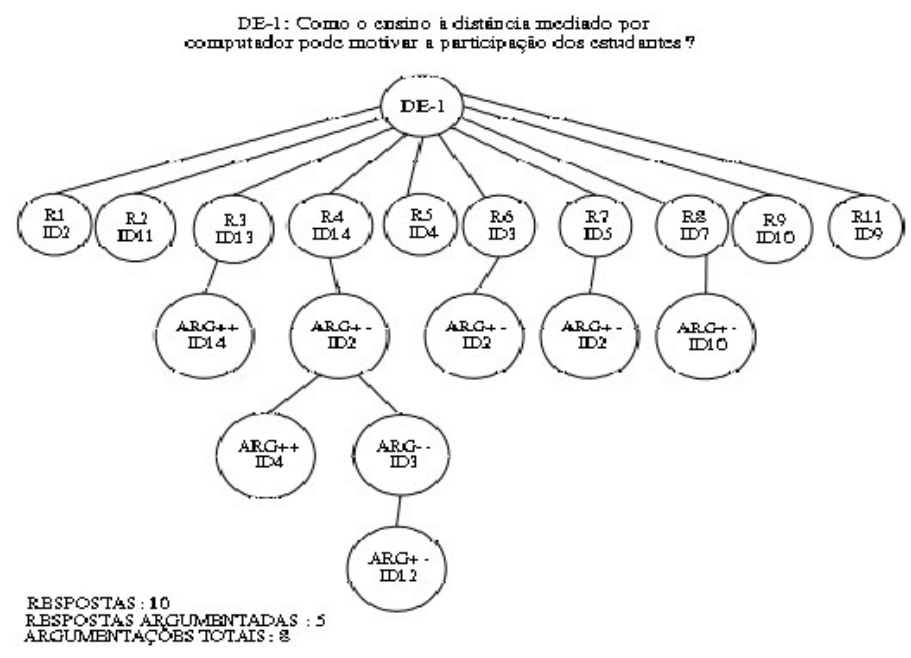

No alto da figura observamos o círculo que representa a pergunta efetuada, DE -1. Logo abaixo do nó principal, as 10 respostas obtidas para esta pergunta (R1 a R11), as quais chamamos de externalizações, em referência ao segundo modo de conversão do conhecimento tácito em explícito preconizado por Nonaka e Takeuchi (1997).

A seguir observamos as argumentações (ARG) apresentadas nos primeiro, segundo e terceiro ciclos de discussões. Como podemos verificar, somente 5 respostas receberam argumentações no primeiro nível, as de número R3, R4, R6, R7 e R8, e somente uma, a resposta R4, recebeu duas novas argumentações, com polemização, no segundo nível, sendo uma do tipo ARG ++ (concordo integralmente - ID 4) e uma do tipo ARG - - (discordo integralmente - ID 3). 
Em função da polemização apontada pelo AMANDA, na resposta R4, o professor foi chamado a intervir (ID 12) e validou, concordando parcialmente (ARG +-), a argumentação apresentada pelo ID 3. Ao pé da figura apresentamos o total de respostas - externalizações (10), a quantidade de respostas argumentadas no primeiro nível (5) e o total geral de argumentações relativas a esta questão (8), nos três níveis.

Com o intuito de esclarecer o conteúdo das árvores e considerando as quatro variáveis quantitativas presentes no fórum: primeira, a quantidade de respostas; segunda, a quantidade de argumentos; terceira, os níveis de argumentação; e quarta, os tipos de argumentações, elaboramos e apresentamos 13 gráficos. A seguir, demonstramos, resumidamente, os resultados do gráfico 22 que explicita a quantidade total de externalizações e de argumentações dadas pelos participantes as 15 perguntas do fórum.

\section{GRÁFICO 22- QUANTIDADE DE INTERAÇÕES TOTAIS}

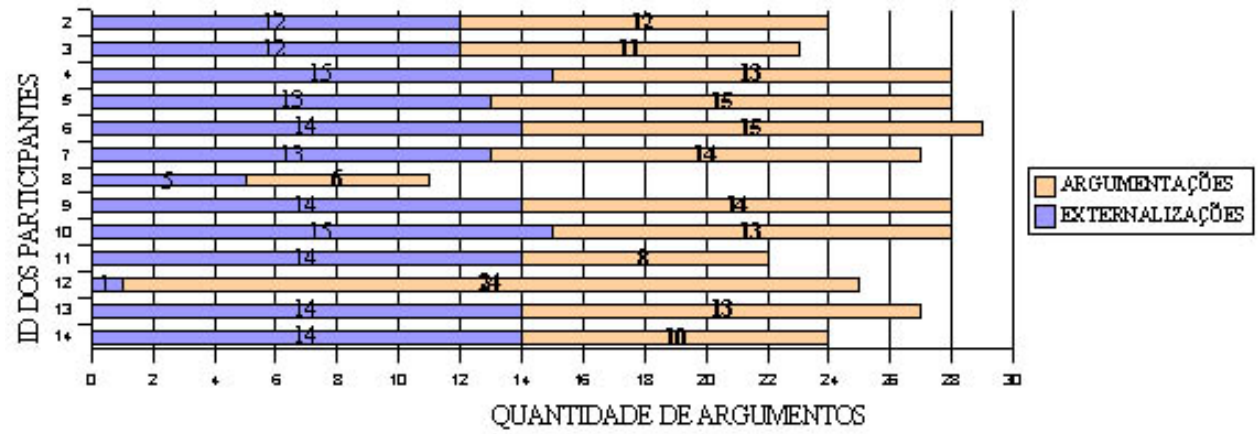

Os resultados do gráfico 22 revelam que, com exceção do participante ID-8, que contribuiu com apenas 11 interações, 5 externalizações e 6 argumentações, foram apresentadas, em média, um total de 26 interações pelos demais membros do grupo. Também podemos observar que o professor respondeu a apenas uma pergunta, ou seja, realizou apenas uma externalização, porém, teve atuação excepcional na apresentação de argumentações, 24.

Embora o AMANDA priorize respostas e argumentações polêmicas, os resultados do gráfico 15 demonstram que o total de argumentações polêmicas foi baixo nessa experiência. 
Como podemos observar no gráfico 15, a maioria das argumentações, 45,66\%, foi de concordância total (ARG ++), sem polêmica alguma; ou de concordância parcial (ARG +-) com alguma ressalva, 45,09\%. Ou seja, nesta experiência, somente 6,35\% das argumentações foram polêmicas (ARG $--)$.

\section{GRÁFICO 15 - PERCENTUAIS DE ARGUMENTAÇÕES POR TIPO}
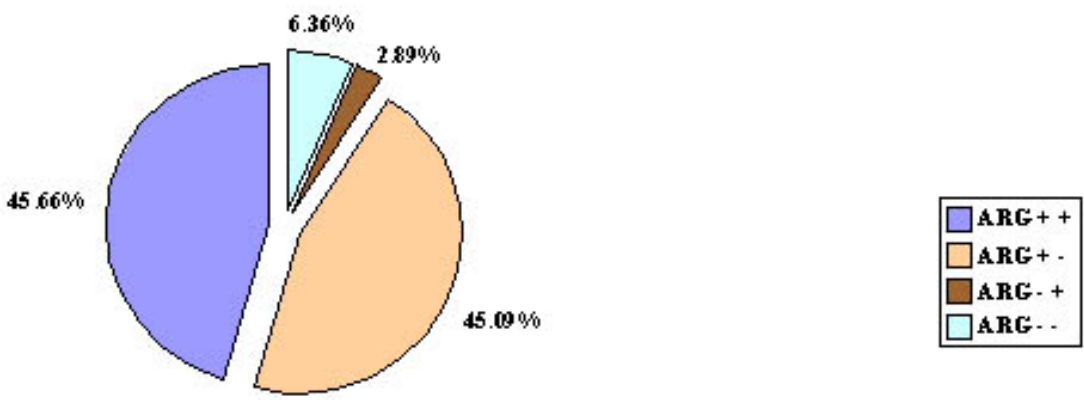

\section{Considerações finais}

A partir da análise do relatório de resultados das discussões, concluímos que o AMANDA apresentou desempenho satisfatório na automação do encaminhamento das questões e dos argumentos a serem discutidos pelos estudantes durante 0 fórum, sem a necessidade da intervenção do professor, pois ao distribuir as fichas de discussão permitiu que os participantes pudessem externalizar seus pensamentos por meio de acordos ou desacordos integrais, ou parciais. Contemplando, assim, o quarto modo de conversão de conhecimento postulado da Teoria da Criação do Conhecimento Organizacional (1997), a externalização.

Por outro lado, seu desempenho ficou prejudicado quando, ao distribuir as questões para serem respondidas entre o grupo, enviou mais de uma vez uma mesma questão, em ficha e ciclos diferentes, para ser respondida por um mesmo participante durante o fórum. Este procedimento provocou entre os estudantes a sensação de estarem respondendo questões repetidas, fator que referencia a necessidade de cuidado pelo professor em definir um número adequado de questões em relação ao número de ciclos de discussão, pois, nessa experiência, a quantidade de questões distribuídas, quinze, foi relativamente excessiva em relação ao número de participantes e de ciclos de discussões realizados, sete.

O fato de o AMANDA distribuir automaticamente as questões e os 
argumentos sem a necessidade da intervenção de um mediador humano, exceto nas questões polêmicas, prejudicou a participação do professor, uma vez que devido ao anonimato este não pôde interagir aberta e diretamente com os estudantes, que também não puderam recorrer às suas orientações para tirar dúvidas durante o fórum.

Esta operação impediu, ainda, que os membros do grupo pudessem observar se durante o fórum estava havendo integração e aumento de conhecimentos, pois o AMANDA não disponibilizou relatórios parciais com os conteúdos/respostas das questões já discutidas e em discussão, apresentou somente fichas individuais com textos anônimos, e para respondê-las os estudantes deviam escolher apenas uma das cinco opções de respostas apresentadas pelo sistema, para cada questão.

Uma outra conclusão diz respeito à interface do AMANDA, ou seja, a falta de mecanismos que permitissem o uso de sons e imagens, por exemplo, impediu uma maior interatividade entre os membros do grupo.

Em resumo, os resultados da experiência indicam que o AMANDA é um ambiente com desempenho adequado para mediar automaticamente discussões entre pessoas, especialistas, que precisam externalizar conhecimentos com a finalidade de tomar decisões práticas, precisas e rápidas, exatamente como ocorre em um exercício com Delphi. Porém, ainda não pode ser considerado um ambiente virtual totalmente adequado à realização de atividades de aprendizagem colaborativa, pois mesmo em fóruns com mediação automatizada, é fundamental haver constante interatividade entre estudante e professores, para que a aprendizagem e a criação de novos conhecimentos explícitos seja continuamente estimulada.

Sabemos que há muito para pesquisar, conhecer e aprender até que possamos entender com maior profundidade como uma experiência de aprendizagem colaborativa em fórum com mediação automatizada pode contribuir integralmente para intensificar a interação entre estudantes, visando a criação de novos conhecimentos. Progressos nessa área dependerão da realização de novas pesquisas científicas.

\section{Referências}

ALCANTARA, P.R.; BERHENS, M. A.; CARVALHO R.G. CD ROM do projeto PACTO: pesquisa em aprendizagem colaborativa com tecnologias interativas (1999 - 2000). Curitiba: Pontifícia Universidade Católica do Paraná, 2001.

BATTEZZATI, S. A Aprendizagem Colaborativa em Fóruns com Mediação Automatizada: 0 ambiente AMANDA. Curitiba. Dissertação (Mestrado) Pontifícia Universidade Católica do Paraná, Curitiba, 2003. 
BEHRENS, M.A. Projetos de aprendizagem colaborativa num paradigma emergente. In: MORAN, J.M.; MASETTO, M.T.; BEHRENS, M.A. Novas tecnologias e mediação pedagógica. Campinas: Papirus, 2000.

ELEUTERIO, M. AMANDA A computational method for mediating asynchronous group discussions. Tese (Doutorado) - PUCPRe University of Compiègne (UTC)Curitiba, 2002.

GIOVINAZZO, R; A. FISCHMANN, A. A. Delphi Eletrônico: uma experiência de utilização da metodologia de pesquisa e seu potencial de abrangência regional. In: CONGRESSO LATINO AMERICANO DE ESTRATÉGIA, 14., Buenos Aires, 2001. Anais... Buenos Aires: [s.n.], 2001.

GIOVINAZZO, R. \& WRIGHT T. C. Modelo de Aplicação da Metodologia Delphi pela Internet: vantagens e ressalvas. Fundação Escola de Comércio Álvares Penteado FECAP. V. 2, n. 2, abr./ jun. 2001 Disponível em http:// www.fecap.br/adm_online/art22/renata.htm

NONAKA, I et al. Criação de conhecimento na empresa. Trad. Ana Beatriz Rodrigues, Proscilla Martins Celeste. 7 ed. Rio de Janeiro, RJ.: Capus, 1997.

PALLOF, R. Construindo comunidades de aprendizagem no ciberespaço. Porto Alegre: Artmed, 2002.

TUROFF, M.; LINSTONE, H. The delphi method. New York: Addison Wesley, 1975.

TUROFF, M.; Hiltz, S. Computer support for group versus individual decisions, IEEE Transactions on Communications, 1982.

WRIGHT, J. Método Delphi. Caderno de Pesquisas em Administração da Universidade de São Paulo. v. 1, n. 12, jul./dez. 2002. Disponível em http:// www.fia.com.br/profuturo/seminarios 